be successfully attacked by the knife as long as the surrounding parts and the adjoining glands have not become contaminated ; for experience too well demonstrates that there is in this disease a power of generally inducing in the surrounding parts a participation in its morbid influence, and thus gradually extending its formidable ravages.

With regard to the other forms of malignant disease, to which the eye, like other organs, is subject, viz., fungus hæmatodes or encephaloid cancer and melanosis, there is ample scope for making remarks, particularly with regard to the former, as it generally occurs in the earlier periods of life, but I have already perhaps trespassed too long on the time and patience of the society to permit any further extension of this paper on the present occasion.

Before concluding, I should wish to remark that the Manchester Eye Hospital was established in the centre of this populous district about the early part of the year 1815, Mr. Wilson being then appointed surgeon, and the late Dr. Hull physician, to the institution. Mr. Barton was soon afterwards appointed a second surgeon, and a year or two afterwards I was appointed a third surgeon. On the retirement of Mr. Wilson from the office about twelve or fourteen years since, two assistant-surgeons were appointed, Messrs. Hunt and Gordon. After the death of the last gentlemen, Mr. Walker succeeded lim, and Dr. Robinson succeeded Dr. Hull. Our patients annually are about 1,500 to near 2,000 in number.

\section{LIGATURE OF THE FEMORAL ARTERY.}

TO THE EDITORS OF THE PROVINCIAL MEDICAL JOURNAI.

Gentlemen,-I was much interested in the perusal of Mr. Jesse's excellent observations on Hæmorrhage after Amputation, in a late number of your valuable publication. The two following cases, which have recently occurred in this institution, fully corroborate his views, viz., that in hæmorrhage from the thigh, when it is found necessary to secure the femoral artery, the ligature should be applied above the origin of the profunda. If that had been done in the first case, there is but little doubt that it would have prevented the necessity of resorting to a second amputation.

\section{Derbyshire General Infirmary,}

I remain, Gentlemen, Your humble servant, R. Dix, House Surgeon. Feb. 22, 1844.

CASE I.-John Noon, aged twenty-two, by trade a joiner, was admitted into the hospital April 24, 1843, with strumous disease of the left knee. As the malady continued to increase, and his health began to suffer, it was deemed advisable to remove the leg above the knee, which operation was performed, by means of a double flap, a fortnight after his admission. He went on very well until May 15, the ninth day after the operation, when hæmorrhage from the stump took place, which was restrained for a time by pressure, and the constant application of cold ; but it occurred again at intervals on the following day; and at one o'clock, a.m., on the 17 th, to such an alarming extent that life was almost lost. Under these circumstances, after he had rallied, it was judged best to tie the femoral artery; this was effected a little below the profunda. Four days afterwards the bleeding again returned profusely, and it was necessary to amputate the limb two inches above the first site of operation. From this period he went on well, and was discharged cured July 17.

CASE II.-John Whitney, a shoemaker, aged seventeen, was admitted November 27, 1843, having disease of the left knee-joint of five years' duration. As he came into the hospital for the purpose of having his leg amputated, the operation was performed ten days after his admission. The stump had nearly healed, and the last ligature came away on the 30th of December; this was followed by hæmorrhage to a considerable extent. After trying the usual means to suppress the bleeding without effect, the femoral artery was tied in the groin above the profunda. From this time he continued progressing towards recovery, and left the infirmary on the 16th instant quite well.

\section{OBSERVATIONS}

ON THE

TREES AND SHRUBS PROPER FOR OUR PROPOSED NATIONAL CEMETERIES.

By Robert Dickson, M.D.

Conservative Power of Vegetation illustratedExceptions in Coniferous and some other TreesApplication.

\section{TO THE EDITORS OF THE PROVINCIAL MEDICAL} JOURNAL.

Gentubmen,-The perusal of an article, which appeared a few weeks since in your valuable Journal, on intra-mural sepulture, suggested to me the following reflections; and should you deem them worthy of a place in your columns, you will oblige me by inserting them.

I remain, Gentlemen, Your obedient servant, Robert Dickson, M.D.

\section{5, Curzon-street, Mayfair,} Feb. 26, 1844.

In the Observations on Mr. Chadwick's Report on Interments in Towns (Provincial Medical Journal, January 6,1844 ), it is proposed, as a remedy for the manifold evils of this custom, that national cemeteries should be provided at proper distances from the metropolis and other large towns. As a very important part of the economy of such cemeteries, it is recommended to keep the ground covered with a thick turf, and planted with shrubs and trees; it being added, "the purifying effects of regetation on the air are well known." The general truth of this statement is unquestionable, but in its practical application it needs some qualification, since, while certain plants exert a purifying influence over the atmosphere, increasing the proportion of oxygen, others, by diminishing its amount, exercise a hurtful power. As it is chiefly plants of the latter kind which are selected for the ornaments of the resting-places of the dead, I propose to offer a few hints to assist in guiding the 